\title{
Peripheral and Autonomic Neuropathy in an Adolescent with Type 1 Diabetes Mellitus: Evidence of Symptom Reversibility after Successful Correction of Hyperglycemia
}

\author{
Joselyn Rojas, Mervin Chávez-Castillo, Wheeler Torres, Carmen Chávez, \\ Vanessa Apruzzese, Mayela Cabrera and Valmore Bermúdez \\ Endocrine and Metabolic Diseases Research Center, Medicine School, \\ Zulia University, Maracaibo, Venezuela
}

Correspondence should be addressed to: Valmore Bermúdez; valmore@gmail.com

Received date: 22 March 2014; Accepted date: 15 May 2014; Published date: 31 December 2014

Academic Editor: Monastiriotis Christodoulos

Copyright (C) 2014. Joselyn Rojas, Mervin Chávez-Castillo, Wheeler Torres, Carmen Chávez, Vanessa Apruzzese, Mayela Cabrera and Valmore Bermúdez. Distributed under Creative Commons CC-BY 3.0

\begin{abstract}
Introduction: Diabetic neuropathy is the most frequent chronic complication of Diabetes Mellitus (DM), currently considered an irreversible end-organ damage complication. The present case concerns a teenage patient, who after effective glycemic control, was shown to regain sensitive and autonomic nerve function. Case Report: An 18-year-old female patient with Type 1 DM with 6 years of evolution since diagnosis and poor metabolic control (HbA1c 13\%) presents to our outpatient clinic with severe sock-pattern burning pain sensation in both lower limbs, which is perceived to have worsened in the previous 6 months despite receiving gabapentin and pregabalin, prescribed in another health center. At physical examination, orthostatic hypotension was evidenced after a fast transition to standing position, tachycardia, muscular hypotrophy of both quadriceps and sural triceps, with a negative Rydel-Seiffert test and a positive Romberg test. Patellar and calcaneal osteotendinous hyporreflexia were found, while hyperalgesia and allodynia to palpation of both feet were present. The RINES-VALCARDI test yielded 8 points at first consultation. She was given patient education concerning her disease and started a strict diet as well as an appropriate insulin therapy to achieve metabolic control. She was treated with duloxetine and capsaicin cream, treatments which she abandoned 6 months later with no observable or measurable relapse of her nerve dysfunctional symptoms; not even one year afterwards. Discussion: This case is unique due to several aspects: The severity of hyperalgesia, and the reversibility of both peripheral and autonomic symptoms after glycemic control and patient education. These elements are fundamental pertaining to reversion of nerve damage.
\end{abstract}

Keywords: Diabetes mellitus, diabetic neuropathy, peripheral diabetic neuropathy, autonomic diabetic neuropathy. 


\section{Introduction}

Chronic complications of Diabetes Mellitus (DM) represent the greatest source of deterioration of lifestyle quality of affected subjects (Shrestha \& Ghimire, 2012). These entities are also linked to most of the expenses associated with DM management, constituting a heavy economic burden for public health systems worldwide (van Dieren et al, 2010). Within the broad spectrum of chronic complications of DM, Diabetic Neuropathy (DN) has the highest prevalence, being present in approximately $50 \%$ of all cases of DM (Boulton et al, 2005), especially those with Type 1 DM (DM1) (van Dieren et al, 2010; Boulton et al, 2005).

Distal Symmetric Polyneuropathy (DSP) is the most prevalent neuropathic disorder, found in $30 \%$ of all patients with DM, and reaching up to $60-70 \%$ in those with long lasting DM since diagnosis (Boulton et al, 2005; Hilz, Marthol \& Neudörfer, 2000). This alteration is progressively disabling, not only due to the pain it generates but because of the risks it imposes on patients, such as the development of foot ulcers, recurrent skin and soft tissues infections (Boulton et al, 2005; Centers for Disease Control, 2011), and the degeneration of osteoarticular structures (Centers for Disease Control, 2011); moreover, the diabetic foot is responsible for up to $75 \%$ of non-traumatic amputations worldwide (Clayton \& Elasy, 2009). On the other hand, Diabetic Autonomic Neuropathy (DAN) comprehends a heterogeneous group of manifestations secondary to the dysregulation of the Autonomic Nervous System (Said, 2007). Although less common than DSP (14-50\% of patients with DM), it implies a high risk of mortality -approximately $50 \%$ within the first 5 years after diagnosis- particularly when autonomic cardiovascular regulation is compromised (Kuehl \& Stevens, 2012; Kamenov \& Traylov, 2012; Karayannis et al, 2012).

The development of diabetic neuropathy relies on the two aspects: hyperglycemia which represents poor metabolic controland genetic susceptibility. It has been suggested that this kind of end-organ damage is proportional to the duration and severity of hyperglycemia (Rogus, Warram \& Krolewski, 2002), yet it is not always the case. Heesom et al. (1998) reported that polymorphisms of the Aldose Reductase gene were involved in the pathogenesis of neuropathy in type $1 \mathrm{DM}$, even in those

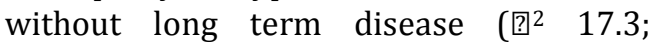
$\mathrm{p}<0.00001)$. Through the years, other genes have been postulated to exacerbate and accelerate diabetic neuropathy, such as Methylenetetrahydrofolate reductase (Yigit, Karakus \& Inanir, 201313), Catalase (Chistiakov et al, 2006), Glutathione peroxidase 1 (Chistiakov et al, 2006), polymorphisms in the 23 adrenoreceptor (Papanas et al, 2007), Poly ADP ribose polymerase (Nikitin et al, 2008), Mn Superoxide Dismutase (Hovnik et al, 2009), and finally, the 4 ApoE allele is associated with a 5-fold risk for severe neuropathy (Monastiriotis et al, 2013). Moreover, several epigenetic modifications have been related to microvascular complications, which also participate during the development and amplification phase of neuropathy (Rafehi, El-Osta \& Karagiannis, 2012), and even influence the capacity for wound healing (Rafehi, El-Osta \& Karagiannis, 2011).

Clinical evaluation of nerve function has been classically done using the Ewing battery of tests (Ewing \& Clarke, 1982), which consists of a series of maneuvers aimed to assess cardiovascular autonomic function. However, other evaluation protocols, such as the RINES-VALCARDI test (Chacín, Jatem \& Rojas, 2009) are applied locally, with good sensitivity when evaluating diabetic neuropathy (Chacín, Jatem \& Rojas, 2009).

Classically, both entities are most prevalent in adult patients, due to the greater possibility of extended DM evolution and a prolonged impaired metabolic control in older patients (Blankenburg et al, 2012). However, the onset of these disorders in an adolescent patient with a relatively short DM personal history since diagnosis highlights the importance of appropriate glycemic management (Nalysnyk, Hernández-Medina \& Krishnarajah, 2010; Soedamah-Muthu, Abbring \& Toeller, 2011). The following case concerns a 
teenage patient with long term DM1 with poor metabolic control, who presents with distal polyneuropathy and autonomic neuropathy.

\section{Case Report}

An 18-year-old female patient, with past medical history of DM1 with six years of evolution since diagnosis and poor metabolic control (HbA1c 13\%), presents to our outpatient clinic with severe sockpattern burning pain in both lower limbs which is perceived to have worsened in the past six months despite receiving gabapentin (400 mg/day) and pregabalin (150 mg/day), prescribed in another health center. Insulin therapy in this patient consisted in a bolus/basal regimen, with insulin Glulisine, 3 IU SC 15 minutes prior main meals, and a basal insulin Glargine component, 16 UI SC at $9 \mathrm{pm}$, referring to poor glycemic control during the last two years, with fasting blood glucose levels around $220 \mathrm{mg} / \mathrm{dL}, 2-\mathrm{H}$ post-prandial glycemia between $280-320 \mathrm{mg} / \mathrm{dL}$ and $\mathrm{HbA} 1 \mathrm{c}$ of $13 \%$. It is noteworthy to mention that the insulin therapy dosage was never completely adjusted, which would explain the chronically worsening of metabolic control during puberty. Additionally, in the last 4 months, she developed weakness and frequent dizziness crisis that worsened with sudden postural changes, and intolerance to cold-room environments. In regards to gastrointestinal symptoms, she referred to post-prandial fullness with occasional vomits with alimentary content, constipation and profuse sweating of the face, scalp, and neck after food ingestion.

Her diabetic debut was an episode of diabetic ketoacidosis, with five successive incidents over the following two years, associated with intentional omission of insulin administration. On the other hand, she also refers to an episode of tonic-clonic seizures due to severe hypoglycemia as a result of insulin overmedication and a lack of nutritional regimen compliance. In the past few years, she was referred to an outpatient gastroenterology consult for acute erosive gastritis and multi-parasitic colitis. Concerning infectious diseases, she referred to 3 episodes of soft tissue infection and 1 urinary tract infection, which required hospitalization for antibiotics and glycemic control. A history of recurrent allergic rhinitis and bacterial otitis media was also documented. In regards to her gynecological history, the patient reported her menarche at age 12 , with 4-day cycles every 28-30 days without dysmenorrhea. At the moment of consultation, she was undergoing psychological therapy due to anxiety and depressive disorders associated with her diagnosis of DM1. The mother denies any relevant first-grade family medical history.

During her physical examination, the patient was observed to be in great pain with evident "facies dolorosa", having a difficult time standing and walking around the examination room. In the general examination protocol, the patient was found conscious, afebrile, with moderate pale. The thorax was normal-sized and expanded without effort, normal vesicular murmur and a respiratory frequency of 20 r.p.m. Breasts were anatomically normal, without nipple discharge. On cardiovascular exploration, heart rate was 100 b.p.m., without murmurs, and associated with orthostatic hypotension (110/70 mmHg lying down, 95/60 mmHg standing, 110/80 mmHg sitting). Pedial and tibial pulses were present and normal on both limbs. The abdomen was slightly painful to palpation in the epigastric region; no visceromegalia was detected by palpation. Genitalia were normal. Regarding anthropometry, weight was measured at $43.2 \mathrm{~kg}$, height $150 \mathrm{~cm}$, and Body Mass Index (BMI) $19.2 \mathrm{~kg} / \mathrm{m}^{2}$.

Neurological examination presented an alert patient oriented in time, place and person. There is no gross evidence of aphasia, apraxia or agnosia. The recent and the remote memory appear normal with good fund of knowledge. Cranial nerves: Pupils are $4 \mathrm{~mm}$, reacting briskly to $2 \mathrm{~mm}$ without afferent pupillary defect. Visual fields are intact to confrontation testing. Funduscopic examination reveals sharp disk margins with normal vasculature. No papilledema, hemorrhages or exudates. Extraocular movements are full and smooth with normal pursuits and saccades. No nystagmus was noted. The face was symmetric and the remaining cranial 
nerves were intact and symmetrical. Lower limbs were further examined, observing discreet muscular hypotrophy with diminished muscle strength (III/V), especially in the quadriceps femoris and triceps surae muscle groups, accompanied by hyperalgesia, hypersensitivity and allodynia (mainly in the feet). Reflexes are $4 / 4$ and symmetrical in the upper extremities, 2/4 and symmetrical at the knees and at the Achilles tendon. Plantar responses were normal bilaterally, but painful. No involuntary movements were noted. Sensation: Intact sensation to gross pinprick with hyperalgesia exacerbation, and mild diminished perception to light touch, vibration (The Rydel-Seiffer tuning fork test was negative) and proprioception (Kästenbauer, 2004) and Semmes-
Weinstein monofilament test (Lee et al, 2003) was not performed due to severe pain and allodynia found at the moment of consultation. Coordination: The patient accomplishes finger-nose-to-finger, heelto-knee-to-shin and rapid alternating movements in a symmetrical fashion without effort, but Romberg's test was positive. Gait and station: The patient walks with a broad-based antialgic gait leaning on the outer edge of the foot (Figure 1). Additionally, the electrocardiographic RINES-VALCARDI test (Chacín, Jatem \& Rojas, 2009) was performed to assess autonomic cardiovascular function, yielding a score of 8 points (Figure 2). Finally, the LANSS pain scale questionnaire was applied, obtaining 19 points.

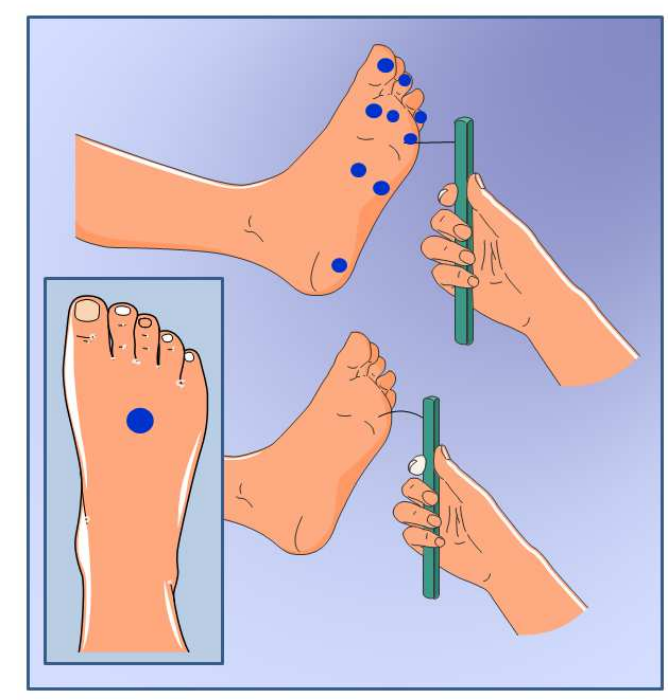

Figure 1: Semmes-Weinstein monofilament test.

This procedure is designed to evaluate the stimulus threshold required for touch perception. The patient must be in supine position and blindfolded. The subject should verbally indicate the moment the pressure from the monofilament is felt. Filaments should be utilized from shortest to longest, placed at a $90^{\circ}$ angle relative to the surface of the assessed site (marked in blue in the illustration), and pressed against the skin for 1.5 seconds. In total, 5 filaments should be used: Lengh $(\mathrm{cm}) 2.83$ and 3.61 are to be applied 3 times in each site; whereas 4.31, 4.56 and 6.65 filaments are applied once. If the patient reports perceiving the pressure, the site is considered "positive". The report should be filed in a specialized illustrative diagram documenting the first filament which was felt on each site, as per the following conventions: a) Green: 2.83; b) Blue: 3.61; c) Purple: 4.31; d) Red: 4.56; e) Red Lines: 6.65. 


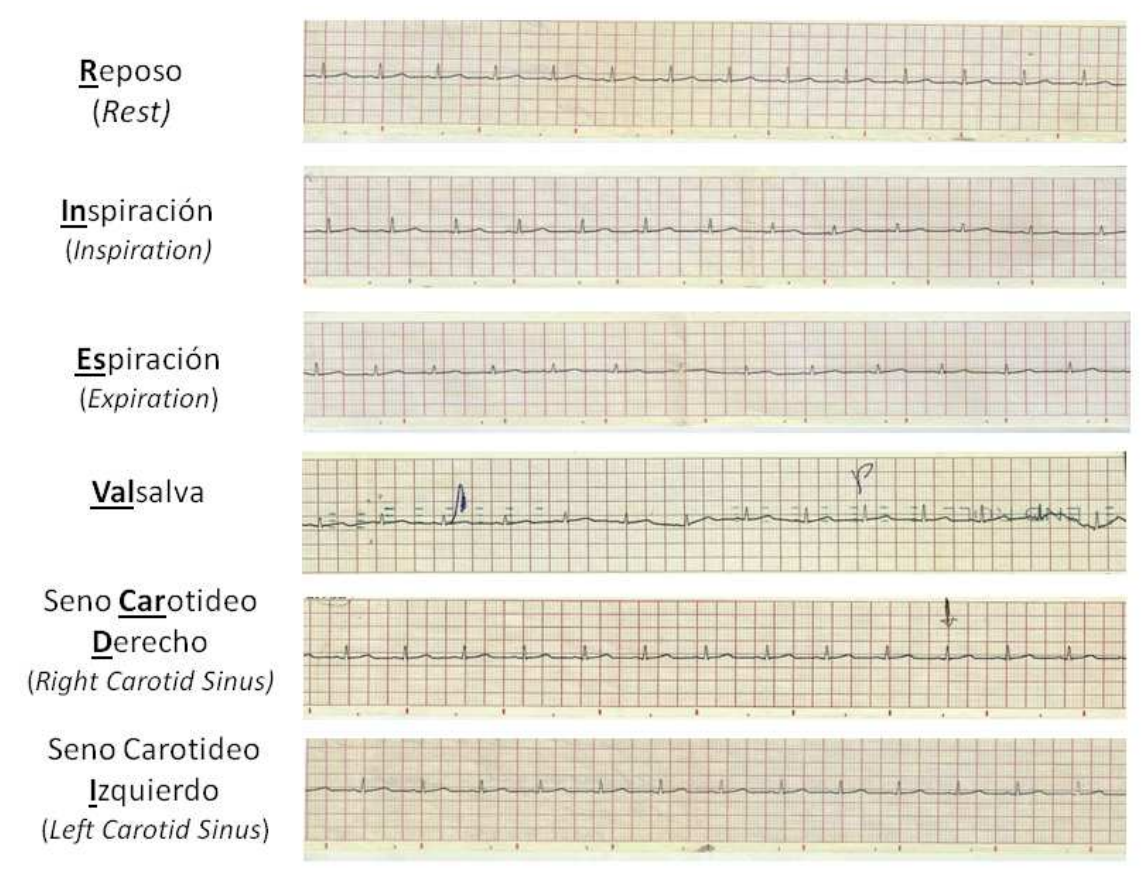

Figure 2: RINES-VALCARDI test.

The standardized lead used to perform test D-II at $10 \mathrm{mV} / \mathrm{mm}$ and $50 \mathrm{~mm} / \mathrm{s}$ speed. After a 3-minute period of rest, the EKG monitoring is started. 15 QRS complexes are registered in each of 6 cycles -which alternate with 2-minute rest periods-, as follows:

- Reposo (Rest): Basal heart rate.

- Inspiración (Inspiration): The patient is asked to perform one deep inspiration.

- Espiración (Expiration): The patient is asked to perform a deep expiration.

- VALsalva: The patient is asked to perform the Valsalva menuver, as follows: "Take a deep breath, keep it in, and push", maintaining the push for at least 10 seconds or as long as it may be tolerated.

- Seno CARotideo Derecho (Right Carotid Sinus): The examinator should gently massage the neck around the right submandibular angle with their second and third fingers.

- Seno carotideo Izquierdo (Left Carotid Sinus): The previous procedure is repeated in the left submandibular angle.

- All R-R' intervals in the EKG registry should be measured in milimeters. From each cycle, the difference between the longest and the shortest interval should be calculated. Finally, all 6 differences are added, yielding the final score. Scores $\leq \mathbf{5}$ are compatible with Cardiac Diabetic Autonomic Neuropathy.

\section{Diagnostic Work-up Analysis}

Laboratory test results are summarized in Table 1. Concerning metabolic control, it was observed that the patient had a fasting glycemia of $143 \mathrm{mg} / \mathrm{dL}$ with HbA1c of $13 \%$, hypertriacylglyceridemia and elevated

\begin{abstract}
pyruvic transaminase. Complementary imaging studies included hepatopancreatobiliary and renal echography with normal results. Ocular computed tomography and retinal fluorescein angiography were both found to be normal.
\end{abstract}


Table 1: Anthropometric and laboratory test values at first consultation.

\begin{tabular}{|l|c|}
\hline \multicolumn{1}{|c|}{ Variable } & Result \\
\hline Weight & $43.2 \mathrm{~kg}$ \\
\hline Height & $1.51 \mathrm{mt}$ \\
\hline Body Mass Index & $18.9 \mathrm{~kg} / \mathrm{m}^{2}$ \\
\hline Total Cholesterol & $243 \mathrm{mg} / \mathrm{dL}$ \\
\hline LDL-C & $151 \mathrm{mg} / \mathrm{dL}$ \\
\hline HDL-C & $32 \mathrm{mg} / \mathrm{dL}$ \\
\hline Triacylglycerides & $781 \mathrm{mg} / \mathrm{dL}$ \\
\hline VLDL-C & $24 \mathrm{mg} / \mathrm{dL}$ \\
\hline Fasting Glycemia & $143 \mathrm{mg} / \mathrm{dL}$ \\
\hline Postprandial Glycemia & $252 \mathrm{mg} / \mathrm{dL}$ \\
\hline HbA1c & $13 \%$ \\
\hline Oxaloacetic Transaminase & $25 \mathrm{U} / \mathrm{mL}$ \\
\hline Pyruvic Transaminase & $36 \mathrm{U} / \mathrm{mL}$ \\
\hline Microalbuminuria & $47 \mathrm{mg} / \mathrm{dL}$ \\
\hline Urea & $46 \mathrm{mg} / \mathrm{dL}$ \\
\hline Creatinine & $1.0 \mathrm{mg} / \mathrm{dL}$ \\
\hline Creatinine Depuration & $153.19 \mathrm{~mL} / \mathrm{min}$ \\
\hline Thyroid Profile & Normal \\
\hline
\end{tabular}

Given this personal history, clinical and laboratory findings, the following diagnoses were proposed: 1) Type 1 Diabetes Mellitus with poor metabolic control; 2) Distal Symmetric Diabetic Polyneuropathy; 3) Diabetic Autonomic Neuropathy, compromising cardiovascular apparatus, gastrointestinal system and the sudomotor complex; 4) Stage 2 Diabetic Nephropathy (microalbuminuria) (Zelmanovitz et al, 2009), and 5) Hypertriacylglyceridemia with Low HDL-C. On this basis, the following management protocol is started: a) Diet therapy according to the American Diabetes Association guidelines (American Diabetes Association, 2014), with increased sodium and water consumption in order to improve orthostatic hypotension; b) Adjustment of insulin therapy to insulin Glulisine (Apidra®) 7 UI SC 15 minutes prior to each meal, and insulin Glargine (Lantus $\left.{ }^{\circledR}\right) 25$ UI SC at 9 pm; with frequent capillary glucometric control (6 times per day) and detailed registry of all food consumption in order to readjust insulin doses depending on carbohydrate intake; c) Ciprofibrate (Hiperlipen $囚) ~ 100 \mathrm{mg} /$ day; d) Duloxetine (Cymbalta $\AA$ ) $30 \mathrm{mg} /$ day; and e) $0.075 \%$ Capsaicin cream prepared in our research center, to be applied from the soles of the feet up to the knees twice per day. Rather impressively, the patient reported improvement of pain by day three after starting this plan, achieving complete pain relief at approximately 4 weeks into treatment.

During one of the successive evaluations (8 months after the first consultation), the patient reported having abandoned Duloxetine treatment after the sixth month, denying recrudescence of pain in this period. Likewise, she also denied feeling dizzy or weak with sudden posture changes. Laboratory tests revealed fasting capillary glycemia levels $<110 \mathrm{mg} / \mathrm{dL}$, with $\mathrm{HbA} 1 \mathrm{c}$ at $6.5 \%$; and BMI of $19.4 \mathrm{~kg} / \mathrm{m}^{2}$, performing daily physical activity without limitations. The Semmes-Weinstein monofilament test was performed with the 5.07 (10-g) filament for evaluation of protective sensation threshold in all 10 assessment sites, with normal results 8 months after starting this protocol. When repeating the RINES-VALCARDI test, results were also normal. At the moment of this publication, the patient presented improvement of microalbuminuria, reaching $18 \mathrm{mg} / \mathrm{dL}$. 


\section{Discussion}

DN is one of the most feared complications of DM, not only due to its inherent painful component (Vinik \& Erbas, 2002), but also due to orthopedic complications such as Charcot's Osteoarthropathy (Papanas \& Maltezos, 2013) which often requires hospital admissions and lower limb amputations (Casellini \& Vinik, 2007). Although neuropathy may develop both in DM1 and Type 2 DM (DM2), its prevalence varies between these categories: DSP is most commonly found in DM2 (50-60.8\%), whereas in DM1, Cardiovascular DAN is more frequent $(60 \%)$, usually coexisting with peripheral polyneuropathy (62.5\%) (Rolim et al, 2009; Van Acker et al, 2009). In both settings, the most important factor for the progression of neuropathy is glycosylated hemoglobin, followed by nephropathy, obesity, low HDL-C and hypertriacylglyceridemia (Van Acker et al, 2009).

DN is classified in two distinct categories (Edwards et al, 2008): a) Diffuse disorders, and b) Focal disorders. The former includes sensorimotor alterations -represented by DSP- and autonomic alterations, as seen in DAN. On the other hand, focal disorders include mononeuropathy, plexopathy, radiculopathy and cranial nerve neuropathy; see Table 2. Peripheral neuropathies are recognized in $60 \%$ of patients with DM (Feldman, 2008), representing one of the greatest risk factors for the development of Charcot's Osteoarthropathy, ulceration and ulterior amputation (Boulton, 2005). In DSP, sensory loss is symmetric and ascendant in a "sock-glove" pattern, proportional to the time of evolution of DM and the successfulness of metabolic control (Vinik, et al. 2003).

Table 2: Classification of Diabetic Neuropathy

\begin{tabular}{|c|l|c|}
\hline Type of Neuropathy & \multicolumn{1}{|c|}{ Clasificación } & Examples \\
\hline \multirow{4}{*}{ Diffuse } & Symmetric & Small-Fiber \\
& Polyneuropathy & Long-Fiber \\
& Diffuse sensorymotor & Mixed \\
\cline { 2 - 3 } & Autonomic Neuropathy & Abnormal pupillary \\
& function \\
& & Sudomotor dysfunction \\
& Genitourinary \\
& & Gastrointestinal \\
& & Cardiovascular \\
& & Maladaptation to \\
& & hypoglycemia \\
\hline Focal & & Mononeuropathy \\
& & Multiple \\
& & mononeuropathy \\
& & Plexopathy \\
& & Radiculopathy \\
& & Craneal neuropathy \\
\hline
\end{tabular}

DAN implicates loss of sympathetic and parasympathetic regulation over the basal function of organs and systems, leading to dysfunction (Edwards et al, 2008). Usually, it appears first in longer nerves such as the Vagus nerve, which encompasses $75 \%$ of all parasympathetic activity (Vinik, Freeman \& Erbas, 2003), and although symptoms tend to present in patients with longer time of evolution, subclinical DAN has been recognized to appear within the first 2 years after diagnosis in patients with DM1; and within 1 year in patients with DM2 (Pfeifer et al, 1984). Within all forms of DAN, the cardiovascular presentation boasts the greatest mortality, associated 
with tachycardia, orthostatic hypotension, sudden cardiac death and silent myocardial infarction, as well as potential compromise of the ability to perform moderate to highintensity physical activity (Boulton et al, 2005). The gastrointestinal system may also be affected, manifesting as retardation of gastric emptying and alternating periods of constipation and diarrhea; whereas involvement of the genitourinary system should be suspected in patients with recurrent urinary infections and neurodysfunctional bladder control, which may be found in $43-78 \%$ of cases (Boulton et al, 2005). Furthermore, DAN is the leading cause of sexual dysfunction in diabetics, with a prevalence of erectile dysfunction of up to $75 \%$ among male patients (Boulton et al, 2005).

The etiology of DN is multifactorial (Sytze Van Dam et al, 2013), including micro- and macroangiopathic events (Jennings et al, 1990) and neurodegenerative changes stemming from defects in vasa vasorum and epi-, peri- and endoneural vessels (Jennings et al, 1990). Among the molecular mechanisms found in this pathologic phenomena are (Sytze Van Dam et al, 2013): The polyol pathway (Oates, 2002), oxidative stress (Pop-Busui, Sima \& Stevens, 2006), advanced glycation (Sugimoto, Yusujima \& Yagihahsi, 2008), nitro-oxidative stress (Fuji et al, 2010), endoplasmic reticulum stress (Cameron, 2013) and TNF-dependent inflammatory mechanisms (González-Clemente et al, 2005). These pathophysiologic components interact synergically, resulting in neuronal death through mechanisms associated with necrosis or apoptosis (Figure 3).

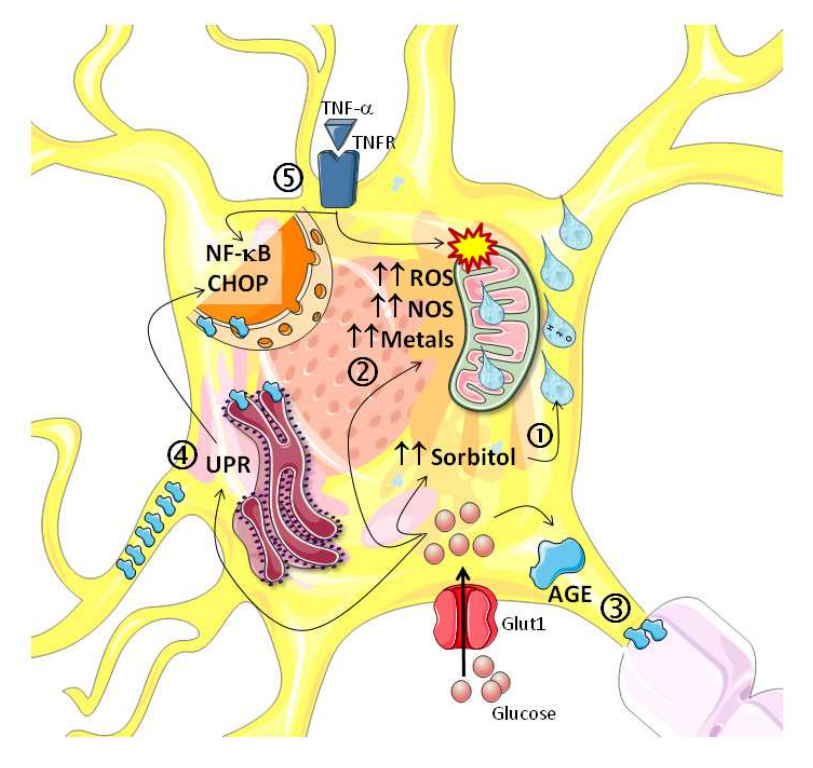

Figure 3: Mechanisms of neuronal damage.

1. Polyol pathway and neuronal edema.

2. Oxidative and Nitrosative stress. Associated with free metal ions and mitchondrial dysfunction.

3. Advanced glycation products and their effect of structural proteins

4. Unfolded Protein response, ending in the induction of proapoptotic protein CHOP.

5. TNF-? proinflammatory actions, including induction of NF-kB, Krebs cycle disturbance and necroptosis.

Although these components are widely recognized as classic features of DN pathophysiology, two novel mechanisms have received special attention in recent years: 1) Lipotoxicity associated with elevated triacylglyceride serum levels, and 2) Schwann cell dysfunction. 
Regarding the former, Wiggin et al. (Wiggin et al, 2009) have reported a correlation between the loss of density of myelinated fibers and hypertriacylglyceridemia, suggesting hyperlipidemia and the consequent lipotoxicity to play a fundamental role in the progression of neuropathy, independently of the type of DM and insulin therapy (Chaturvedi et al, 2001). These findings correlate with cellular events as reported by Lupachyk et al. (2012), who found higher concentrations of triacylglycerides and non-esterified fatty acids to be linked with impaired nerve conduction and modifications in sensorial function in experimental models with Zucker $f a / f a$ rats; associated with induction of nitrosative stress, particularly in Schwann cells. In our case, the patient presented with hypertriacylglyceridemia, which was successfully treated with diet and fibric acid derivative (Ciprofibrate).

Schwann cell damage may be especially important, given their active participation in the preservation of nerve action potentials, owing to their role as axon insulators through myelination, conservation of axonal caliber, and control of sodium ions within the neurotransmission mechanism (Eckersley, 2002). Indeed, this preservation of axonal architecture includes maintenance of paranodal and juxtaparanodal domains, and distribution of voltage-dependent $\mathrm{Na}^{+}$ and $\mathrm{K}^{+}$channels (Salzer, Brophy \& Peles, 2008). Structural defects in Schwann cells and myelin sheaths are key elements in the development of DN (Zenker, Ziegler \& Chrast, 2013). These cells are excellent targets for insulin activity due to their constitutive expression of insulin receptor, IRS- 1 and GLUT 1 and 3, as opposed to the expression of GLUT 1, 3, 4 and 8 in axons (Thorens \& Mueckler, 2010). Diabetesinduced glycotoxicity is related to a reduction in lactate transport, which lowers ATP synthesis and in turn increases free radical production and disorders in $\mathrm{Na}^{+} / \mathrm{K}^{+}$ATPase pump and $\mathrm{Ca}^{++} / \mathrm{Na}^{+}$ exchanger activity, ultimately leading to alterations in activation voltages (Pellerin \& Magistretti, 2003).

In this context, it is convenient to describe the types of nerve fibers and their interactions with support cells, such as Schwann cells and neuroglia. Peripheral nerves may be sensitive, motor or autonomous, and are structurally constituted by an axon, the axolemma, a myelin sheath, a neurolemma or sheath of Schwann, and the endoneurium (Manzano, Giuliano \& Nóbrega, 2008). These fibers are further subclassified in three groups according to their width, myelination and function (Figure 4) (Manzano, Giuliano \& Nóbrega, 2008).

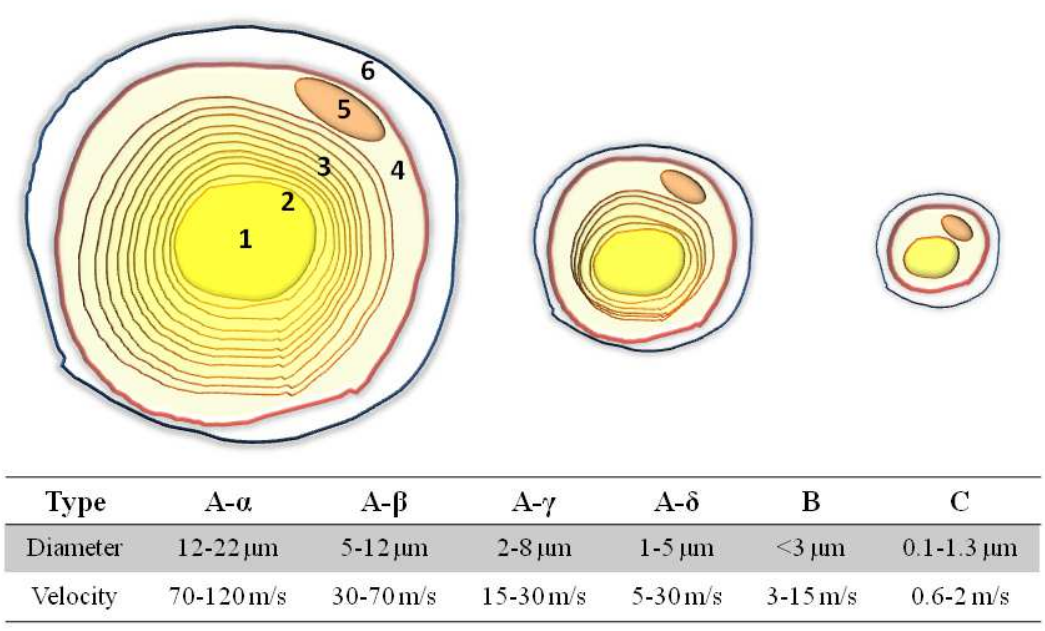

Figure 4: Types of peripheral nerve fibers. 
1. Axon, the thin long projection of the neuron which conducts action potentials away from its cell body. 2. Axolemma, the cell membrane surrounding the axon, which mantains its transmembrane potential by virtue of its ion channels. 3. Myelin sheath, the enwrapping outgrowth of Schwann cells which envelops and insulates axons. 4. Neurolemma, the outermost cytoplasmic ring of Schwann cells. 5. Nucleus of Schwann cell. 6. Endoneurium, loose layer of connective tissue which encloses nerve fibers.

The classic symptoms of DSP are hyperalgesia and allodynia, characterized by abnormal reactions to non-noxious cutaneous contact, which trigger electric hyperactivity in pain neural pathways (Basic-Kes et al, 2009). The underlying modifications in neuron physiology include changes in ion flux patterns, synaptic connectivity and neurotransmitter receptor profiles (Zenker, Ziegler \& Chrast, 2013; Thorens \& Mueckler, 2010; O'Connor et al, 2004), overall known as neuronal plasticity (O'Connor et al, 2004). The neuropathic pain experienced by DM patients stems from slower conduction speed and the onset of spontaneous depolarization in polymodal axons of Type $C$ fibers, and it is mediated chiefly by Substance $\mathrm{P}$ (O'Connor et al, 2004), a tachynin-like neuropeptide responsible for nociception. Indeed, the main fibers involved in this process are group C type I fibers which contain Substance $P$ and tyrosine kinase $\mathrm{A}$, and are responsive to capsaicin and acidosis (Hökfelt, Pernow \& Wahren, 2001), being highly sensitive to local $\mathrm{pH}$ changes (Imme \& McClesky, 2001); in contrast to group C type II fibers which are dependent on ATP/P2X and protons (Hökfelt, Pernow \& Wahren, 2001).

Although the post-receptor pathway for Substance $P$ activity remains poorly described, it has been demonstrated that after binding to its NK1 receptor, it induces the release of reactive oxygen species from the mitochondrial compartment, which in turn act as second messengers, modulating spontaneous activity of TPRV1 vanilloid receptors, inducing pain (Linley et al, 2012). This pathway exploited in the mechanism of action of capsaicin, a highly irritative phenolic amide found in chili peppers (Solanaceae family, Capsicum genus) (Govindaraian, 1986), leading to depletion of Substance $P$, reserves in nociceptive neurons through interference of its synthesis (Burks, Buck \& Miller, 1985), downregulation of its receptors (Marvizón et al, 2003), and finally, repression of the expression of NK1 and TRPV receptors (Kunde, Crawford \& Geraghty, 2013). In light of these properties, capsaicin was used in our patient as a coadjuvant treatment along with duloxetine, garnering satisfactory control of hyperalgesia and allodynia.

On a different matter, the risk of developing DAN has been reported to be higher in the presence of peripheral neuropathy (OR 2.53), increased HbA1c (OR 1.69), elevated serum triacylglycerides (OR 1.58), high waist circumference (OR 1.36), microalbuminuria (OR 1.24), and pubertal-onset DM (OR 1.08) (Voulgari et al, 2011). Moreover, it is thought to be more frequent in DM1 patients due to their longer life expectancy since the advent of recombinant insulin analogues with distinct and diverse activity profiles, accompanied by early diagnosis and adequate nutritional management (American Diabetes Association, 2014; Massin et al, 1999). Although the benefits offered by these analogues have allowed for their successful implementation, achieving metabolic control (HbA1c $<7 \%$ ) is often a more difficult endeavor in these patients, particularly in younger subjects due to age-related factors such as a lack of acceptance and adherence to therapeutic plans, deficient parental integration to these protocols, and puberty-associated factors (Rosenbloom et al, 2008).

In the situation of pediatric patients reaching adulthood, the transition from parental care towards self-care and management is an especially relevant element as it depends on the psychological maturity of the adolescent (Rosenbloom et al, 2008; Peters \& Laffel, 2011). In these individuals, depression associated to factors such as strict nutritional and 
medication regimes, peer pressure and sexual development may deeply affect treatment compliance (Rosenbloom et al, 2008; Peters \& Laffel, 2011). In the case we report, the patient was found to have voluntarily neglected insulin administration on several occasions, culminating in the development of ketoacidosis and hospitalization. Indeed, these psychological aspects are pivotal in order to accomplish metabolic goals and decelerate the onset of chronic complications of hyperglycemia (Rosenbloom et al, 2008).

In pediatric ages, neuroautonomic manifestations are diverse and should be surveyed in every consultation (Table 3). Gastrointestinal symptoms are rarely observed in this demography, although a slight correlation has been reported between gastric emptying time and hyperglycemia $(\mathrm{r}=0.54, \mathrm{p}=0.08)$ (Vazeou et al, 2004), being more frequent in females, particularly in obese subjects with a history of recurrent epigastric pain (Sfarti et al, 2010). On the other hand, early signs of cardiac DAN include diastolic dysfunction in patients with DM1 and microangiopathy (Vazeou et al, 2008), attenuation of the baroreceptor reflex and pulse pressure in correlation with the duration of the disease (Abd El Dayem, Battah \& Soliman, 2011).

Table 3: Clinical signs associated with Diabetic Autonomic Neuropathy.

\begin{tabular}{|c|c|}
\hline Organ & Sign \\
\hline Pupils & Impaired pupillary adaptation to \\
& lowered light \\
\hline Sudomotor & Dry skin \\
& Anhydrosis \\
& Intolerance to warm temperature \\
Digestion-related perspiration
\end{tabular}

Although the progression of the disease may be slowed, it is not considered to be preventable in all patients due to the multifactorial nature of the process; however, glycemic control remains the most important goal in this aspect (American Diabetes Association, 2014,Park, Park \& Baek, 2004). While all medication used in the management of neuropathy is implemented on the basis of altering pathophysiologic mechanisms of the disease, no protocols have been established regarding drug combinations in this context (Boucek, 2006). One of the most interesting aspects of this case was the remission of pain-related symptoms after starting on duloxetine and capsaicin, remaining still after suspension of both drugs, suggesting reversibility of neuronal damage even in cases as severe as ours. 
In order to assess this progression, DSP should be evaluated annually utilizing methods such as (American Diabetes Association, 2014): a) Exploration of pain sensation to pinching (mechanic pain threshold) and touch sensation to cotton swabs, both transmitted through Type C and A-? fibers; b) Vibration perception threshold of Type A-? fibers, assessed with $128 \mathrm{~Hz}$ tuning forks; c) Semmes-Weinstein monofilament test for the evaluation of deep protective sensation by Pacinian corpuscules; and d) Calcaneal/Patellar reflex exploration, assessing proprioceptive sensation by Golgi tendon organs. The combination of these techniques offers over $87 \%$ sensitivity for detecting DSP (American Diabetes Association, 2014). The utilization of tuning forks renders higher sensitivity and positive predictive value when compared to neurothesiometers (Kästenbauer et al, 2004). Furthermore, vibratory methods offer 53\% sensitivity and 99\% specificity, while superficial pain assessment through the pinching method offers 59\% sensitivity and $97 \%$ specificity (Perkins et al, 2001).

Nevertheless, the Semmes-Weinstein monofilament test appears to offer the smallest margin of error, as well as require minimal training (Lee et al, 2003). This technique encompasses evaluation of 10 distinct sites in feet, with sensitivity varying between $57-93 \%$, specificity 75 $100 \%$, positive predictive value $84-100 \%$ and negative predictive value $36-94 \%$ for the diagnosis of DSP (Freng, Schlösser \& Sumpio, 2009). Moreover, different kinds of filaments yield distinct predictive results depending on the sites they are used in; for example, application of the 4.3/2-g monofilament renders remarkable diagnostic values in the hallux and the $5^{\text {th }}$ metatarsal, with $60 \%$ sensitivity and $73.8 \%$ specificity (Kamei et al, 2005) with positive results being linked to alterations in vibratory perception and syncope, reflecting small-fiber damage (Perkins et al, 2001). These data have led to the proposal of limiting the sites of evaluation in order to guarantee more homogeneous results (Boucek, 2006). Particularly, the use of the $10 \mathrm{~g}$ monofilament in 3 areas offers several advantages, including a higher risk in ulceration depth (Tan, 2010) and a lack of perception of this filament is regarded as an independent risk factor for ulceration, due to the loss of protective sensitivity (Tan, 2010).

Finally, nerve conduction assessment techniques and electromyography (Brij et al, 1996) may be implemented in the diagnosis of DSP, regarded as the most objective tests to this end (Hsu et al, 2012; Said 2007), returning documentation on the type of neuronal injury and its localization (Boulton 2005; Said 2007). In symptomatic DN, findings include longer conduction speeds due to demyelination, and lower action potentials, owing to axonal loss (Boulton 2005; Tan, 2010; Said 2007). The application of needle electromyography is reserved for assessment of abnormal spontaneous potentials and exploration of motor unit configuration, as required in cases of generalized neuropathy, atrophy of proximal muscle groups, and radiculopathy (Boulton 2005; Said 2007).

Additionally, nerve conduction studies are valuable tools in the evaluation of nerve preservation, yet they may not be applicable in all cases, such as in polyneuropathy affecting small fibers, since these do not participate in sensorial action potentials (Said 2007). In DN, axonal loss with reduction or absence of action potentials may be observed, predominating in lower limbs, although according to the stage of progression, it may involve the hands; however, many DM patients may present nerve conduction abnormalities without any clinical signs. Weisman et al. (2013) reported the predictive profile of the conduction speed of individual nerves and combinations in the diagnosis of DSP, where the conduction speed in the peroneal and the sural nerve identified cases with sensitivities of $80 \%$ and $83 \%$ respectively, and $89 \%$ and $72 \%$ specificity, correspondingly. Furthermore, the sum of the $F$ wave of tibial latency plus peroneal conduction speed, and the sum of 3 conduction speeds of the lower limb (sural peroneal and tibial) predicted a 4-year incidence with $79-81 \%$ sensitivity and 63 $77 \%$ specificity. 
There are other methods for pain and quality of life assessment, such as DN4 (Douleur Neuropathique 4 Questions) for pain, which boasts $95 \%$ sensitivity and 96.6\% specificity (Unal-Cevik, Sarioglu-Ay \& Evcik, 2010); the LANSS Pain Scale (Leeds Assessment of Neuropathic Symptoms and Signs) with $70.2 \%$ sensitivity and $96.6 \%$ specificity (UnalCevik, Sarioglu-Ay \& Evcik, 2010; Bennet, 2001); and the McGill Pain Questionnaire (Burckhardt \& Jones, 2003). Although these methods allow for a quick screening and personal assessment of pain in correlation to clinical findings, confirmation through tuning fork assessment, monofilament test or anatomic-specific pulse and reflex exploration should always be sought.

On the other hand, DAN assessment is recommended starting 5 years after diagnosis of DM1 (American Diabetes Association, 2014), surveying the following manifestations: Tachycardia at rest, exercise intolerance, orthostatic hypotension constipation, gastroparesis, erectile dysfunction, intolerance to hypoglycemia and sweating dysfunction (American Diabetes Association, 2014). The RINES-VALCARDI test (Chacín, Jatem \& Rojas, 2009) is a diagnostic tool developed in Venezuela by Dr. Luis Chacín in 1981, wherein heart rate is registered with a conventional 12-lead electrocardiograph in 6 1-minute cycles: at rest, during deep inspiration, during expiration, while performing the Valsalva maneuver, and while softly massaging the left and right carotid sinuses (Figure 2). Results $\leq 15$ points are compatible with cardiac DAN. Indeed, in comparison to non-diabetic subjects, diabetic individuals with RINESVALCARDI scores $\leq 15$ points presented greater frequency of postural hypotension (40\%), loss of morning urinary urgency $(53,3 \%)$, periodic nocturnal diarrhea (40\%) and erectile dysfunction $(44,4 \%)$ (Figuera et al, 1997). A new, less cumbersome version of the test has been recently proposed by the same research group (Chacín et al, 2009), which involves the utilization of a pulse oximeter for heart rate monitoring during each of the 6 cycles, registering this parameter at 0 ", 15", 30", $45^{\prime \prime}$ and $60 "$. For each cycle, the difference between the highest and lowest values is calculated, and finally all 6 differences are added to obtain a final score. With this form of test, scores $<27$ points appear to detect cardiac DAN with $60.86 \%$ sensitivity, $86.61 \%$ specificity, $92.45 \%$ positive predictive value and $45.6 \%$ negative predictive value.

Regarding pharmacologic therapy of $\mathrm{DN}$, a wide array of drugs with diverse mechanisms of action may be utilized, including (Attala et al, 2010): Inhibition of monoamine reuptake, calcium channel blockers N-Methyl-D-Aspartate receptor antagonists, Substance P-depleting agents, opioid agonists, GABA modulators, and NSAIDs. Indication of the drugs is issued in a progressive, stratified fashion including combinations, since monotherapy appears to offer relief to less than $50 \%$ of cases (Weisman et al, 2013). First-line medication includes (Vinik \& Casellini, 2013): ?2-? agonists (pregabalin or gabapentin), serotonin-norepinephrine reuptake inhibitors (SNRI) (duloxetine) and tricyclic antidepressants (TCA). If pain management is inadequate or these are contraindicated, second-line treatment involves the following combinations (64): TCA with SNRI, TCA with ?2-? agonists or SNRI with ?2-? agonists. Finally, if control remains insufficient, an opioid is added into the combination. The corresponding efficacy rates and numbers needed to treat (NNT) are (Vinik, 2010): a) TCA OR 22.2 and NNT 1.5-3.5; b) Duloxetine OR 2.6 and NNT 5.7-5.8; c) Traditional Anticonvulsants OR 5.3 and NNT 2-9-4.3; and e) Opioids OR 4.3 and NNT 2.6-3.9.

According to the American Neurology Academy (Bril et al, 2011) and the Toronto Consensus Panel on Diabetic Neuropathy Management (Tesfaye et al, 2011), Level A of recommendation is Pregabalin (300-600 $\mathrm{mg}$ /day), whereas all other medication is considered Level B: Gabapentin 900-3600 $\mathrm{mg} /$ day, Duloxetine 60-120 mg/day, Amitriptyline 25-100 mg/day, Sodium Valproate 500-1200 mg/day, Tramadol $210 \mathrm{mg} /$ day, and $0.075 \%$ Capsaicin cream. TCA are contraindicated in patients with glaucoma, orthostatic hypotension, overweight and cardiovascular disease. Duloxetine is contraindicated in subjects with hepatic disease, and ?2-? agonists 
contraindicated in subjects with edema and weight gain (Bril et al, 2011).

Achievement of metabolic goals accompanied by possible reversibility of neural damage was observed in these cases, where patient reeducation, psychological therapy, adequate weight gain, adherence to insulin therapy, improvement of lipid profile and inclusion of physical activity in daily routine served as key components for restitution of the functional anatomy of nerve tissue. Evidence of neuropathic damage reversibility exists in contexts such as cachectic DN (Tesfaye et al, 2011), characterized by intense neuropathic pain and wasting syndrome associated with the initiation of insulin therapy and the sudden lowering of HbA1c (Weintrob et al, 1997). This clinical picture is accompanied by finings of nervous potential ablation and slower conduction speeds in both motor and sensitive nerves (Weintrob et al, 1997; Kihara et al, 1994). Although its pathophysiology is yet to be elucidated, Grewal et al. (2006) have described the first report of objective confirmation of damage reversibility through nerve conduction studies during pain crises within the cachectic phase, suggesting this reversion to be dependent on replenishment of neuronal normoxia.

It is well-known that the application of intensive insulin therapy allows for the restoration of intraaxonal sodium ion transit patterns, in turn improving action potential capacity (Sima \& Brismar, 1985). Furthermore, the reversion of hyperglycemia-triggered damage in DN may also be associated with the restoration of myoinositol metabolism defects and sodium permeability gradients (Brismar, Sima \& Greene, 1987). Although several mechanisms are involved in axonal damage (Sytze Van Dam et al, 2013), these specific components share the polyol pathway as an etiopathogenic element. Williamson et al. (Williamson et al, 1993) have proposed hyperglycemia to generate the same effects as ischemia through the sorbitol pathway termed hyperglycemic pseudohypoxiasuch as an elevation of the NADH/NAD ${ }^{+}$ ratio, which induces electric, mechanic and vascular dysfunction with a consequent rise in lactate production. Moreover, it has been reported that the main mediator of oxidative neuronal damage is Aldose Reductase (AR), a key enzyme in the polyol pathway (Chung et al, 2003).

The increase of NADH due to AR and its consequent redox imbalance augment diacylglycerol synthesis and Protein Kinase C activity, leading to lowered $\mathrm{Na}^{+} / \mathrm{K}^{+}$ ATPase pump activity, myoinositol depletion, induction of prostaglandin synthesis, and production of reactive oxygen species and nitric oxide (Brismar, Sima \& Greene, 1987). Moreover, this state of pseudohypoxia may trigger the expression of HIF-1 through nitric oxide acting on the genetic regulation of this protein (Marfella et al, 2002), enabling its participation in aberrant angiogenesis, a classic feature found in diabetic patients (Kota et al, 2012). Because AR is predominantly expressed in Schwann cells (Tomlinson \& Gardiner, 2008), this aspect of neuropathic damage does not begin in neurons themselves, but rather in their myelination and support cellular system.

Considering this succession of cellular and clinical events, a possible interventional window may be outlined, wherein the main source of damage leading to conduction impairment first appears in Schwann cells (Zenker, Ziegler \& Chrast, 2013); with this state of refractoriness and/or sodium gradient alteration being sufficient to modify axonal conduction patterns and "stunned" neurons, before the onset of overt clinical manifestation (Arnold et al, 2013). This phenomenon may also be observed in autonomic nerves, as reported by Kiyono et al. (2005) who found that a progressive potentiation of the polyol pathway induces sympathetic fiber dysfunction, associated with downregulation of norepinephrine transporters, a loss of cardiac neuroautonomic control. The early detection of the neuropathic phenomenon and adequate, quick and precise control of hyperglycemia may allow for reversion of the events previously described, by rescuing neurons from stunning and impeding the development of the irreversible histopathologic changes seen in DN. 
In conclusion, because $\mathrm{DN}$ is one of the most concerning complications - owing not only to its complex pathophysiology, but also to its booming incidence in the last decade (Mohsin et al, 2005) - early detection, strict glycemic control and management of amplifying factors are extremely valuable tools in order to delay progression and potentially favor reversibility of this disease.

\section{Acknowledement}

This work was supported by research grant № CC-0437-10-21-09-10 from the Technological, Humanistic, and Scientific Development Council, University of Zulia, and research grant №. FZ-0058-2007 from Fundacite-Zulia.

\section{Disclosure}

The authors have are no conflicts of interest to disclose.

\section{References}

1. Abd El Dayem, S. M., Battah, A. A, Soliman, R. A. (2011) Natural progression of cardiac autonomic neuropathyin patients with type 1 diabetes: a four-year follow-up study. Anadolu Kardiyol Derg, 11(3), 224231.

2. American Diabetes Association. (2014) Diagnosis and Classification of Diabetes Mellitus. Diabetes Care, 37 (Supplement 1), S81-S90.

3. Arnold, R., Kwai, N., Lin, CS., Poynten, A. M., Kiernan, M. C., Krishnan, A. V. (2013) Axonal dysfunction prior to neuropathy onset in type 1 diabetes. Diabetes Metab Res rev, 29 (1), 53-59.

4. Attala, N., Cruccu, G., Baron, R., Haanpä, M., Hansson, P., Jensen, T. S., Nurmiko, T. (2010) EFNA guidelines on pharmacology treatment of neuropathic pain: 2010 revision. Eur J Neurol, 17, 1113-1123.

5. Basic-Kes, V., Zavoreo, I., BosnarPuretie, M., Ivankovic, M., Birunjac, M., Govori, V., Demarin, V. (2009)
Neuropathic pain. Acta Clin Croat, 48 (3), 359-365.

6. Bennet M. (2001) The LANSS pain scale: the Leeds assessment of neuropathic symptoms and signs. Pain, 92 (1-2), 147-157.

7. Blankenburg, M, Kraemer, N, Hirschfeld, G, Krumova, E. K., Maier, C, Hechler, T, Aksu, F, Magerl, W, Reinehr, T, Wiesel, T, Zernikow, B. (2012) Childhood diabetic neuropathy: functional impairment and non-invasive screening assessment. Diabet Med, 29 (11), 1425-1432.

8. Boucek P. (2006) Advanced diabetic neuropathy: a point of no return? Rev Diabetic Stud, 3 (3), 143-150.

9. Boulton, A. J. M. (2005) Managament of diabetic peripheral neuropathy. Clin Diabetes, 23 (1), 9-15.

10. Boulton, A. J. M., Vinik, A. I., Arezzo, J. C., Bril, V, Feldman, E. L., Freeman, R, Malik, R. A., Maser, R. E., Sosenko, J. M., Ziegler, D; American Diabetes Association. (2005) Diabetic Neuropathies. A statement by the American Diabetes Association. Diabetes Care, 28 (4), 956-962.

11. Brij, V., Werb, M.R., Greene, D. A., Sima, A. A. (1996) Single-fiber electromyography in diabetic peripheral polyneuropathy. Muscle Nerve, 19 (1), 2-9.

12. Bril, V., England, J., Franklin, G.M., Backonja, M., Cohen, J., Del Toro, D., Feldman, E., Iverson, D.J., Perkins, B., Russell, J.W., Zochodne, D; American Academy of Neurology; American Association of Neuromuscular and Electrodiagnostic Medicine; American Academy of Physical Medicine and Rehabilitation. (2011) Evidencebased guideline: treatment of painful diabetic neuropathy: report of the American Academy of Neurology, the American Association of Neuromuscular and Electrodiagnostic Medicine, and the American Academy 
of Physical Medicine and Rehabilitation. Neurology, 76 (20), 1758-1765.

13. Brismar, T., Sima, A. A, Greene, D. A. (1987) Reversible and irreversible nodal dysfunction in diabetic neuropathy. Ann Neurol, 21 (5), 504507.

14. Burckhardt, C. S., Jones, K. D. (2003) Adult Measures of Pain: The McGill Pain Questionnaire (MPQ), Rheumatoid Arthritis Pain Scale (RAPS), Short-Form McGill Pain Questionnaire (SF-MPQ), Verbal Descriptve Scale (VDS), Visual Analog Scale (VAS), and West Haven-Yale Multidisciplinary Pain Inventory (WHYMPI). Arthritis Rheumatism, 49 (S5), S96-S104.

15. Burks, T. F., Buck, S. H., Miller, M. S. (1985) Mechanisms of depletion of substance P by capsaicin. Fed Proc, 44 (9), 2531-2534.

16. Cameron, N. E. (2013) Role of endoplasmic reticulum stress in diabetic neuropathy. Diabetes, 62 (3), 696-697.

17. Casellini, C. M., Vinik, A. (2007) Clinical manifestations and current treatment options for diabetic neuropathy. Endocr Pract, 13 (5), 550-566.

18. Centers for Disease Control and Prevention, National diabetes fact sheet: national estimates and general information on diabetes and prediabetes in the United States. 2011 ed, Atlanta, GA: US Department of Health and human Services, Center for disease Control and Prevention, 2011.

19. Chacín Álvarez, L. F., Jatem, E., Rojas, C. (2009) Diagnóstico de la neuropatía autonómica cardiovascular diabética mediante la monitorización de la frecuencia cardíaca (Rines Valcardi-Monitor). Diabetes Internacional, 1 (1), 9-14.
20. Chacín, L. F., Jatem, E, Rojas, C. (2009) Diagnóstico de la neuropatía autonómica cardiovascular diabética mediante la monitorización de la frecuencia cardíaca (Rines ValcardiMonitor). Diabetes Int, 1 (1), 9-14.

21. Chaturvedi, N., Sjoelie, A. K., Porta, M., Aldington, S. J., Fuller, J. H., Songini, M., Kohner, E. M; EURODIAB Prospective Complications Study. (2001) Markers of insulin resistance are strong risk factors for retinopathy incidence in type 1 diabetes. Diabetes Care, 24 (2), 284- 289.

22. Chistiakov, D. A., Zotova, E. V., Savost'anov, K. V., Bursa, T. R., Galeev, I. V., Strokov, I. A., Nosikov, V. V. (2006) The 262T $>C$ promoter polymorphism of the catalase gene is associated with diabetic neuropathy in type 1 diabetic Russian patients. Diabetes Metab, 32 (1), 63-68.

23. Chung, S. S., Ho E. C., Lam, K. S, Chung, S. K. (2003) Contribution of polyol pathway to diabetes-induced oxidative stress. J Am Soc Nephrol, 14 (8 Suppl 3), S233-S236.

24. Clayton, W, Elasy, T. A. (2009) A Review of the Pathophysiology, Classification, and Treatment of Foot Ulcers in Diabetic Patients. Clinical Diabetes, 27 (2), 52-58.

25. Eckersley, L. (2002) Role of the Schwann cell in diabetic neuropathy. Int Rev Neurobiol, 50, 293-321.

26. Edwards, J. L., Vincent, A. M., Cheng, H. T., Feldman, E. L. (2008) Diabetic neuropathy: mechanisms to management. Pharmacol Ther, 120 (1), 1-34.

27. Ewing, D. J., Clarke, B. F. (1982) Diagnosis and management of diabetic autonomic neuropathy. $\mathrm{Br}$ Med J, 285, 916-18.

28. Feldman, E. L. (2008) Diabetic neuropathy. Curr Drug Targets, 9 (1), 1-2. 
29. Feng, Y., Schlösser, F. J., Sumpio, B. E. (2009) The Semmes Weinstein monofilament examination as a screening tool for diabetic peripheral neuropathy. J Vasc Surg, 50 (3), 675682.

30. Figuera Ch Y. J., Tovar, E., Tineo, A. (1997) Neuropatía autonómica cardiovascular en pacientes diabéticos no insulino dependientes. Saber, 9 (1), 25-31.

31. Fujii, H., Kono, K., Nakai, K., Goto, S., Komaba, H., Hamada, Y., Shinohara, M., Kitazawa, R., Kitazawa, S., Fukagawa, M. (2010) Oxidative and nitrosative stress and progression of diabetic nephropathy in type 2 diabetes. Am J Nephrol, 31 (4), 342352.

32. González-Clemente, J. M., Mauricio, D., Richart, C., Broch, M., Caixàs, A., Megia, A., Giménez-Palop, O., Simón, I., Martínez-Riquelme, A., GiménezPérez, G., Vendrell, J. (2005) Diabetic neuropathy is associated with activation of the TNF-alpha system in subjects with type 1 diabetes mellitus. Clin Endocrinol, 63 (5), 525-529.

33. Govindaraian, V. S. (1986) Capsicum-production, technology, chemistry, and quality. Chemistry of the color, aroma, and pungency stimuli. Crit Rev Food Sci Nutr, 24 (3), 245-355.

34. Grewal, J., Bril, V., Lewis, G., Perkins, B. A. (2006) Objective evidence for the reversibility of nerve injury in diabetic neuropathic cachexia. Diabetes Care, 29 (2), 472-473.

35. Heesom, A. E., Millward, A, Demaine, A. G. (1998) Susceptibility to diabetic neuropathy in patients with insulin dependent diabetes mellitus is associated with a polymorphism at the $5^{\prime}$ end of the aldose reductase gene. J Neurol Neurosug Psychiatry, 64 (2), 213-216.

36. Hilz, M. J., Marthol, H, Neundörfer, B. (2000) Diabetic somatic polyneuropathy. Pathogenesis, clinical manifestations and therapeutics concepts. Fortschr Neurol Psychiatr, 68 (6), 278-288.

37. Hökfelt, T., Pernow, B., Wahren, J. (2001) Substance P: a pioneer amongst neuropeptides. J Intern Med, 249 (1), 27-20.

38. Hovnik, T, Dolzan, V, Bratina, N. U., Podkrajsek, K. T., Battelino, T. (2009) Genetic polymorphisms in henes encoding antioxidant enzymes are associated with diabetic retinopathy in type 1 diabetes. Diabetes Care, 32 (12), 2258-2262.

39. Hsu, W.C., Chiu, S. Y., Yen, A. M., Chen, L. S., Fann, C. Y., Liao, C. S., Chen, H. H. (2012) Somatic neuropathy is an independent predictor of all- and diabetes-related mortality in type 2 diabetic patients: a population based 5 year follow up study (KCIS). Eur J Neurol, 19 (9), 1192-1198.

40. Imme, D. C., McClesky, E. W. (2001) Lactate enhances the acid sensing $\mathrm{Na}+$ channel on ischemia-sensing neurons. Nat Neurosci, 4 (9), 869-870.

41. Jennings, P. E., Nightingale, S., Lawson, N., Hoffman, P., Williamson, J.R, Bernett, A. H. (1990) Impact of microangiopathy on chronic symptomatic peripheral neuropathy. Diabetes Res, 13 (2), 51-54.

42. Kamei, N., Yamane, K., Nakanishi, S., Yamashita, Y., Tamura, T., Ohshita, K., Watanabe, H., Fujikawa, R., Okubo, M., Kohno, N. (2005) Effectiveness of Semmes-Weinstein monofilament examination of diabetic peripheral neuropathy screening. $J$ Diabetes Complications, 19 (1), 47-53.

43. Kamenov, Z. A., Traykov, L.D. (2012) Diabetic autonomic neuropathy. $A d v$ Exp Med Biol , 771, 176-193.

44. Karayannis,

G, Cokkinos, D.V., Skoularigis, J, Triposkiadis, F. (2012) Diabetic cardiovascular autonomic 
neuropathy: clinical implications. Expert Rev Cardiovasc Therapy, 10 (6), 747-765.

45. Kästenbauer, T, Sauseng, S, Brath, H, Abrahamian, H, Irsigler, K (2004) The value of the Rydel-Seiffer tuning fork as a predictor of diabetic polyneuropathy compared with the neurothensiometer. Diabet Med, 21 (6), 563-567.

46. Kihara, M., Zollman, P. J., Smithson, I. L., Lagerlund, T. D., Low, P. A. (1994) Hypoxic effect of exogenous insulin on normal and diabetic peripheral nerve. Am J Physiol, 266 (6 Pt 1), E980E985.

47. Kiyono, Y., Kajiyama, S., Fujiwara, H., Kanegawa, N., Saji, H. (2005) Influence of the polyol pathway on norepinephrine transporter reduction in diabetic cardiac sympathetic nerves: implications for heterogeneous accumulation of MIBG. Eur J Nucl Med Mol Imaging, 32 (8), 993-997.

48. Kota, S. K., Meher, L. K., Jammula, S., Kota, S. K., Krishna, S.V., Modi, K. D. (2012) Aberrant angiogenesis: the gateway to diabetic complications. Indian J Endocrinol Metab, 16 (6), 918-930.

49. Kuehl, M, Stevens, M. J. (2012) Cardiovascular autonomic neuropathies as complications of diabetes mellitus. Nat Rev Endocrinol, 8(7), 405-416.

50. Kunde, D. A., Crawford, A., Geraghty, D. P. (2013) Tachykinin (NK1, NK2, and NK3) receptor; transient receptor potential vanilloid 1 (TRPV1) and early transcription factor, cFOS, mRNA expression in rat tissues following systemic capsaicin treatment. Regul Pept 183C, 35-41.

51. Lee, S, Kim, H, Choi, S, et al. (2003) Clinical usefulness of the two-site Semmes-Weinstein monofilament test for detecting diabetic peripheral neuropathy. J Korean Med Sci, 18 (1), 103-107.

52. Linley, J. E., Ooi, L., Pettinger, L., Kirton, H., Boyle, J. P., Peers, C., Gamper, N. (2012) Reactive oxygen species are second messengers of neurokinin signaling in peripheral sensory neurons. Proc Natl Acad Sci U $S A, 109$ (24), E1578-E1586.

53. Lupachyk, S., Watcho, P., Hasanova, N., Julius, U., Obrosova, I. G. (2012) Triglyceride, NEFA and prediabetic neuropathy: role for oxidativenitrosative stress. Free Radic Biol Med, 52 (8), 1255-1263.

54. Manzano, G. M., Giuliano, L. P., Nóbrega, J. A. (2008) A brief historical note on the classification of nerve fibers. Arq NeuroPsiquiatr; 66 (1), 117-119.

55. Marfella, R., D'Amico, M., Di Filippo, C., Piegari, E., Nappo, F., Esposito, K., Berrino, L., Rossi, F., Giugliano, D. (2002) Myocardial infarction in diabetic rats: role of hyperglycaemia on infarct size and early expression of hypoxia-inducible factor 1. Diabetologia. 45 (8), 1172-1181.

56. Marvizón, J. C., Wang, X., Matsuka, Y., Neubert, J. K., Spigelman, I. (2003) Relationship between capsaicin-evoke Substance P release and neurokinin 1 receptor internalization in the rat spinal cord. Neuroscience, 118 (2), 535-545.

57. Massin, M. M., Derkenne, B., Tallsund, M., Rocour-Brumioul, D., Ernould, C., Lebrethon, M.C., Bourguignon, J.P. (1999) Cardiac autonomic dysfunction in diabetic children. Diabetes Care, 22 (11), 1845-1850.

58. Mohsin, F., Craig, M. E., Cusumano, J., Chan, A. K., Hing, S., Lee, J. W., Silink, M., Howard, N. J., Donaghue, K. C. (2005) Discordant trends in microvascular complications in adolescents with type 1 diabetes from 1990 to 2002. Diabetes Care, 28 (8), 1974-1980. 
59. Monastiriotis, C., Papanas, N., Trypsianis, G., Karanikola, K., Veletza, S., Maltezos, E. (2013) The $\varepsilon 4$ allele of the APOE gene is associated with more severe peripheral neuropathy in type 2 diabetic patients. Angiology, 64 (4), 451-5.

60. Nalysnyk, L, Hernández-Medina, M, Krishnarajah, G. (2010) Glycaemic variability and complications in patients with diabetes mellitus: evidence from a systematic review of the literature. Diabetes Obes Metab, 12 (4), 288-298.

61. Nikitin, A. G., Chudakova, D. A., Strokov, I. A., Bursa, T. R., Chistiakov, D. A., Nosikov, V. V. (2008) Leu54Phe and Val762Ala polymorphoisms in the poly(ADP-ribose)polymerase-1 gene are associated with diabetic polyneuropathy in Russian type 1 diabetic patients. Diabetes Res Clin Pract , 79 (3), 446-452.

62. O'Connor TM, O'Connell J, O'Brien DI, Goode T, Bredin CP, Shanahan F. The role of substance $\mathrm{P}$ in inflammatory disease. J Cell Physiol 2004;201:167180.

63. Oates, P. J. (2002) Polyol pathway and diabetic peripheral neuropathy. Int Rev Neurobiol, 50, 329-392.

64. Papanas, N., Papatheodorou, K., Papazoglou, D., Kotsiou, S., Christakidis, D., Maltezos, E. (2007) An insertion/deletion polymorphism in the alpha2B adrenoceptor gene is associated with peripheral neuropathy in patients with type 2 diabetes mellitus. Exp Clin Endocrinol Diabetes, 115 (5), 327-30.

65. Papanas, N, Maltezos, E. (2013) Etiology, pathophysiology and classifications of the diabetic Charcot foot. Diabetic Foot Ankle, 4; DOI: 10.3402/dfa.v4i0.20872.

66. Park, T. S., Park, J. H., Baek, H.S. (2004) Can diabetic neuropathy be prevented? Diabetes Res Clin Pract, 66 (Supplement 1), S53-S56.
67. Pellerin, L., Magistretti, P. J. (2003) How to balance the brain budget while spending glucose differently. $J$ Physiol, 546 (Pt 2), 325.

68. Perkins, B. A., Olaleye, D., Zinman, B., Bril, V. (2001) Simple screening tests for peripheral neuropathy in the diabetes clinic. Diabetes Care, 24 (2), 250-256.

69. Peters A, Laffel L, The American Diabetes Association Transitions Working Group. (2011) Diabetes Care for emerging adults: recommendations for transition from pediatric to adult diabetes care systems. Diabetes Care, 34 (11), 2477 2485.

70. Pfeifer, M. A., Weinberg, C. R, Cook, D. L, Reenan, A, Halter, J. B., Ensinck, J. W., Porte, D. Jr. (1984) Autonomic neural dysfunction in recently diagnosed diabetic subjects. Diabetes Care, 7 (5), 447-453.

71. Pop-Busui, R., Sima, A., Stevens, M. (2006) Diabetic neuropathy and oxidative stress. Diabetes Metab Res Rev , 22 (4), 257-273.

72. Rafehi H, El-Osta A, Karagiannis T. C. (2011) Genetic and epigenetic events in diabetic wound healing. Int Wound $J, 8$ (1), 12-21.

73. Rafehi, H, El-Osta, A, Karagiannis, T. C. (2012) Epigenetic mechanisms in the pathogenesis of diabetic foot ulcers. $J$ Diabetes Complications, 26 (6), 554561.

74. Rogus, J. J., Warram, J. H., Krolewski, A. S. (2002) Genetic studies of late diabetic complications: the overlooked importance of diabetes duration before complication onset. Diabetes, 51 (6), 1655-1662.

75. Rolim, L. C., Sá, J. R., Chacra, A. R., Dib, S. A. (2009) Clinical heterogeneity and coexistence of diabetic neuropathies: difference and similarities between types 1 and 2 diabetes mellitus. Arq 
Bras Endocrinol Metabol, 53 (7), 818824.

76. Rosenbloom, A. L., Silverstein, J. H., Amemiya, S., Zeitler, P., Klingensmith, G. J.; International Society for Pediatric and Adolescent Diabetes. (2008) ISPAD Clinical Practice Consensus Guidelines 2006-2007. Type 2 diabetes mellitus in the child and adolescent. Pediatric Diabetes, 9 (5), 512-526.

77. Said, G. (2007) Diabetic neuropathy a review. Nat Clin Pract Neurol, 3 (6), 331-340.

78. Salzer, J. L. Brophy, P. J, Peles, E. (2008) Molecular domains of myelinated axons in the peripheral nervous system. Glia, 56 (14), 15321540.

79. Sfarti, C., Trifan, A., Hutanasu, C., Cojocariu, C., Singeap, A. M., Stanciu, C. (2010) Prevalence of gastroparesis in type 1 diabetes mellitus and its relationship to dyspeptic symptoms. $J$ Gastrointestinal Liver Dis, 19 (3), 279284.

80. Shrestha, P, Ghimire, L. A. (2012) Review about the Effect of Lifestyle Modification on Diabetes and Quality of Life. Glob J Health Sci, 4 (6), 185190.

81. Sima, A. A., Brismar, T. (1985) Reversible diabetic nerve dysfunction: structural correlates to electro'hysiological abnormalities. Ann Neurol, 18 (1), 21-29.

82. Soedamah-Muthu, S. S., Abbring, S, Toeller, M. Diet, Lifestyle and Chronic Complications in Type 1 Diabetic Patients. S.S. Soedamah-Muthu, S. Abbring and M. Toeller (2011). Diet, Lifestyle and Chronic Complications in Type 1 Diabetic Patients, Type 1 Diabetes - Complications, Pathogenesis, and Alternative Treatments, Prof. Chih-Pin Liu (Ed.), ISBN: 978-953-307-756-7, InTech, DOI: 2011. Available at: http://www.intechopen.com/books/t ype-1-diabetes-complicationspathogenesis-and-alternativetreatments/diet-lifestyle-andchronic-complications-in-type-1diabetic-patients

83. Sugimoto, K., Yusujima, M., Yagihahsi, S. (2008) Role of advanced glycation end products in diabetic neuropathy. Curr Pharm Des, 14 (10), 953-961.

84. Sytze Van Dam, P., Cotter, M. A., Bravenboer, B., Cameron, N. E. (2013) Pathogenesis of diabetic neuropathy: focus on neurovascular mechanisms. Eur J Pharmacol, 719 (1-3), 180-186.

85. Tan, L.S. (2010) The clinical use of the $10 \mathrm{~g}$ monofilament and its limitation: a review. Diabetes Res Clin Pract, 90 (1), 1-7.

86. Tesfaye, S., Vileikyte, L., Rayman, G., Sindrup, S., Perkins, B., Baconja, M., Vinik, A., Boulton, A; on behalf of the Toronto Expert Panel on Diabetic Neuropathy. (2011) Painful diabetic peripheral neuropathy: consensus recommendations on diagnosis, assessment and management. Diabetes Metab Res Rev 2011; DOI; 10.1002/dmrr.1225.

87. Thorens, B., Mueckler, M. (2010) Glucose transporters in the $21^{\text {st }}$ century. Am J Physiol Endocrinol Metab, 298 (2), E141-E145.

88. Tomlinson, D. R., Gardiner, N. J. (2008) Glucose neurotoxicity. Nat Rev Neurosci, 9 (1), 36-45.

89. Unal-Cevik, I., Sarioglu-Ay, S., Evcik, D. A. (2010) comparison of the DN4 and LANSS questionnaires in the assessment of neuropathic pain: validity and reliability of the Turkish version of DN4. J Pain, 11 (11), 11291135.

90. Van Acker, K, Bouhassira, D, De Bacquer, D, Weiss, S, Matthys, K, Raemen, H, Mathiue, C, Colin, I. M. (2009) Prevalence and impact on quality of life of peripheral neuropathy with or without 
neuropathic pain in type 1 and type 2 diabetic patients attenting hospital outpatients clinics. Diabetes Metab, 35 (3), 206-213.

91. van Dieren, S, Beulens, J. W., van der Schouw, Y. T., Grobbee, D. E., Neal, B. (2010) The global burden of diabetes and its complications: an emerging pandemic. Eur J Cardiovasc Prev Rehabil,17 (Supplement 1), S3-S8.

92. Vazeou, A., Papadopoulou, A., Miha, M., Drakatos, A., Georgacopoulos, D. (2008) Cardiovascular impairment in children, adolescents, and young adults with type 1 diabetes mellitus (T1DM). Eur J Pediatr, 167 (8), 877884.

93. Vazeou, A., Papadpoulou, A., Papadimitriou, A., Kitsou, E., Stathatos, M., Bartsocas, C. S. (2004) Autonomic neuropathy and gastrointestinal motility disorders in children and adolescents with type 1 diabetes mellitus. $J$ Pediatr Gastroenterol Nutr, 38 (1), 61-65.

94. Vinik, A, Erbas, T. Neuropathy. In Handbook of Exercise in Diabetes. 2nd ed. Ruderman N, Devlin JT, Kriska A, Eds. Alexandria, VA, American Diabetes Association 2002, p. 463496.

95. Vinik, A. (2010) The approach to the management of the patient with neuropathic pain. J Clin Endocrinol Metab, 95 (11), 4802-4811.

96. Vinik, A. I., Casellini, C. M. (2013) Guidelines in the management of diabetes nerve pain: clinical utility of pregabalin. Diabetes Metab Synd Obesity, 6:57-78.

97. Vinik, A. I., Freeman, R, Erbas, T. (2003) Diabetic autonomic neuropathy. Semin Neurol, 23 (4), 365-372

98. Vinik, A. I., Maser, R. E., Mitchell, B. D., Freeman, R. (2003) Diabetic autonomic neuropathy. Diabetes Care, 26 (5), 1553-1579.
99. Voulgari, C., Psallas, M., Kokkinos, A., Argiana, V., Katsilambros, N., Tentolouri,s N. (2011) The association between cardiac autonomic neuropathy with metabolic and other factors in subjects with type 1 and type 2 diabetes. I Diabetes Complications, 25 (3), 159-167.

100. Weintrob, N., Josefberg, Z., Galazar, A., Vardi, P., Karp, M. (1997) Acute painful neuropathic cachexia in a young type 1 diabetic woman: a case report. Diabetes Care, 20 (3), 290-291.

101. Weisman, A., Bril, V., Ngo, M., Lovblom, L. E., Halpern, E. M., Orszag, A., Perkins, B. A. (2013) Identification and prediction of diabetic sensorimotor polyneuropathy using individual and simple combinations of nerve conduction study parameters. PLoS ONE, 8 (3), e58783.

102. Weisman, A., Bril, V., Ngo, M., Lovblom, L. E., Halpern, E. M., Orszag, A., Perkins, B. A. (2013) Identification and prediction of diabetic sensorimotor polyneuropathy using individual and simple combinations of nerve conduction study parameters. PLoS ONE, 8 (3), e58783.

103. Wiggin TD, Sullivan KA, Pop-Busui R., Amato, A., Sima, A. A., Feldman, E. L. (2009) Elevated triglycerides correlate with progression of diabetic neuropathy. Diabetes, 58 (7), 16341640.

104. Williamson, J. R., Chang, K., Frangos, M., Hasan, K.S., Ido, Y., Kawamura, T., Nyengaard, J. R., van den Enden, M., Kilo, C., Tilton, R. G. (1993) Hyperglycemic pseudohypoxia and diabetic complications. Diabetes, 42 (6), 801-813.

105. Yigit, S, Karakus, N, Inanir, A. (2013) Association of MTHFR gene C677T mutation with diabetic peripheral neuropathy and diabetic retinopathy. Mol Vis, 19, 1626-1630.

106. Zelmanovitz, T, Gerchman, F, Balthazar, A. P., Thomazelli, F. C., Matos, J. D., Canani, L. H. (2009) 
Diabetic nephropathy. Diabetol Metab Syndr, 1 (1):10.
107. Zenker, J., Ziegler, D., Chrast, R. (2013) Novel pathogenic pathways in diabetic neuropathy. Neurosciences, 36 (8), 439-449. 